\section{Public Health} Genomics
Public Health Genomics 2016;19:193-202

DOI: $10.1159 / 000444478$
Received: July 15, 2015

Accepted: February 5, 2016

Published online: March 31, 2016

\title{
Do Public Involvement Activities in Biomedical Research and Innovation Recruit Representatively? A Systematic Qualitative Review
}

\author{
Jonas Lander $^{\mathrm{a}}$ Tobias Hainz $^{\mathrm{a}, \mathrm{b}}$ Irene Hirschberg ${ }^{\mathrm{a}} \quad$ Sabine Bossert ${ }^{\mathrm{a}}$ \\ Daniel Strech ${ }^{\mathrm{a}}$ \\ ${ }^{a}$ Institute for History, Ethics and Philosophy of Medicine, Hannover Medical School, Hannover, and \\ ${ }^{\mathrm{b}}$ Institute for History, Theory and Ethics of Medicine, Johannes Gutenberg University Mainz, Mainz, Germany
}

\section{Key Words}

Biomedical research - Biotechnology · Public consultation .

Public engagement · Public involvement · Representation ·

Representativeness $\cdot$ Study sample

\begin{abstract}
Background: Public involvement activities (PIAs) may contribute to the governance of ethically challenging biomedical research and innovation by informing, consulting with and engaging the public in developments and decisionmaking processes. For PIAs to capture a population's preferences (e.g. on issues in whole genome sequencing, biobanks or genome editing), a central methodological requirement is to involve a sufficiently representative subgroup of the general public. While the existing literature focusses on theoretical and normative aspects of 'representation', this study assesses empirically how such considerations are implemented in practice. It evaluates how PIA reports describe representation objectives, the recruitment process and levels of representation achieved. Methods: PIA reports were included from a systematic literature search if they directly reported a PIA conducted in a relevant discipline such as genomics, biobanks, biotechnology or others. PIA reports were
\end{abstract}

analyzed with thematic text analysis. The text analysis was guided by an assessment matrix based on PIA-specific guidelines and frameworks. Results: We included 46 relevant reports, most focusing on issues in genomics. 27 reports (59\%) explicitly described representation objectives, though mostly without adjusting eligibility criteria and recruiting methods to the specific objective. 11 reports (24\%) explicitly reported to have achieved the intended representation; the rest either reported failure or were silent on this issue. Conclusion: Representation of study samples in PIAs in biomedical research and innovation is currently not reported systematically. Improved reporting on representation would not only improve the validity and value of PIAs, but could also contribute to PIA results being used more often in relevant policy and decision-making processes.

(c) 2016 S. Karger AG, Basel

\section{Introduction}

Public involvement activities (PIAs) are a way of establishing a dialogue between science and society regarding ethical, legal and social challenges in biomedical research and innovation [1]. PIAs further aim to increase trans-

\section{KARGER}

E-Mail karger@karger.com

www.karger.com/phg
(C) 2016 S. Karger AG, Basel

$1662-4246 / 16 / 0194-0193 \$ 39.50 / 0$
Daniel Strech

Hannover Medical Schoo

Carl-Neuberg-Strasse 1

DE-30625 Hannover (Germany)

E-Mail strech.daniel@mh-hannover.de 
parency around publicly relevant issues in genomics research (including biobanks) or emerging biotechnologies (including genome editing or synthetic biology) and, more generally, enable different types of public participation in corresponding decision-making and governance processes [2]. To do so, a range of PIAs have been developed, including public information, consultation, deliberation and participation. Examples are the British Columbia biobank deliberation [3] and the CARTaGENE Project on establishing a genetic database [4]. These and other PIA approaches employ a range of engagement methods such as focus groups, deliberative group discussions or citizen juries [5-7].

Genetics and genomics research, such as pharmacogenetics, is a good example to highlight the relevance of PIAs. First, technological advance of these subjects is associated with low levels of public understanding and awareness due to the complexity involved. For instance, informed consent constitutes a challenge for pharmacogenomics as the data created may apply to follow-up research projects with different research questions that the study participants did not initially consent to [8]. Second, genetics and genomics research may find application in inherently new areas for which there is insufficient experience to judge the ethical and societal issues that may arise, as well as the degree of societal acceptance [9]. Application of new technologies in clinical practice is also a matter of acceptable/maximum cost, which in turn is a matter of societal and political debate [8]. Finally, genetics and genomics require professionals (researchers, clinicians, tech industry, etc.) to support public understanding and debate: Only if this is given, the public may provide necessary support such as prioritizing research questions and brining up new subjects $[9,10]$.

A number of studies have examined the 'involvement' aspect of PIAs from a normative theoretical standpoint, in particular by discussing rationales, objectives, methods and challenges (such as missing impact evaluations or translation of PIA-related results into policy) $[5-7,11]$. The definition of 'public', or rather whom exactly to involve in a PIA, is another core aspect, as it directly affects every method, objective and outcome of public involvement [12-14]. For most PIAs, a subgroup of the relevant population must be identified. Hence, one of the most important questions is how to involve individuals who are in some way representative of the target population.

For instance, if the objective of a PIA were to gather the full spectrum of people's arguments for refusing participation in a biomedical research study, the sample used would need to represent the widest possible range of in- dividual characteristics. If, on the other hand, a PIA aimed to survey public attitudes towards a specific biomedical innovation, for the results to be generalizable it would be desirable to involve a statistically representative subgroup of the public. Hence, there are different concepts of 'representation', and which is best depends on the specific purpose and method of a PIA. Further, public involvement guidelines highlight the importance of representation to accurately reflect patients'/the public's preferences and needs, to ensure that the PIA effectively informs decision-making processes and to avoid the potential impacts of selection bias. Achieving representation may therefore involve a systematic process of identifying, selecting, recruiting and possibly retaining study participants [15].

Extensive literature exists on different modes of representation and their relevance to PIAs [16-23]. These discussions mostly refer to theoretical and normative notions regarding what kind of representation is appropriate for different means of public involvement and how representation can be achieved. The objective of this review is different insofar as it assesses how such considerations have been operationalized in a systematically derived sample of PIA reports that deal with issues in biomedical research and innovation. Specifically, the objectives are to assess (a) what types of representation were aimed at in different PIA reports, (b) which eligibility criteria and recruiting methods were used to achieve representation, (c) whether representation in the study sample was achieved and (d) whether and how potential limitations of the actual study sample were recognized and addressed by the PIA authors, either during the conduct of the PIA or when drawing conclusions.

\section{Methods}

Database-Specific Search, Selection of Studies and Data Analysis

As part of a broader research project studying PIAs in biomedical research and innovation, we identified relevant PIA reports via a systematic literature search in PubMed, Scopus and PsycINFO (fig. 1, table 1, online suppl. information 1; for all online suppl. material, see www.karger.com/doi/10.1159/000444478). For details on the search strategy see [24]. For the subsequent thematic text analysis of selected reports, an assessment matrix was developed based on a literature review of PIA-specific guidelines and frameworks [25-28]. The matrix had four core categories: (a) general information, (b) PIA concept, (c) background and theoretical framework and (d) methods. Subcategories, such as 'representation/sample aim', 'recruiting method' and 'study limitations', covered the main conceptual and methodological issues of public involvement discussed in the PIA guidelines (online suppl. information 2). 


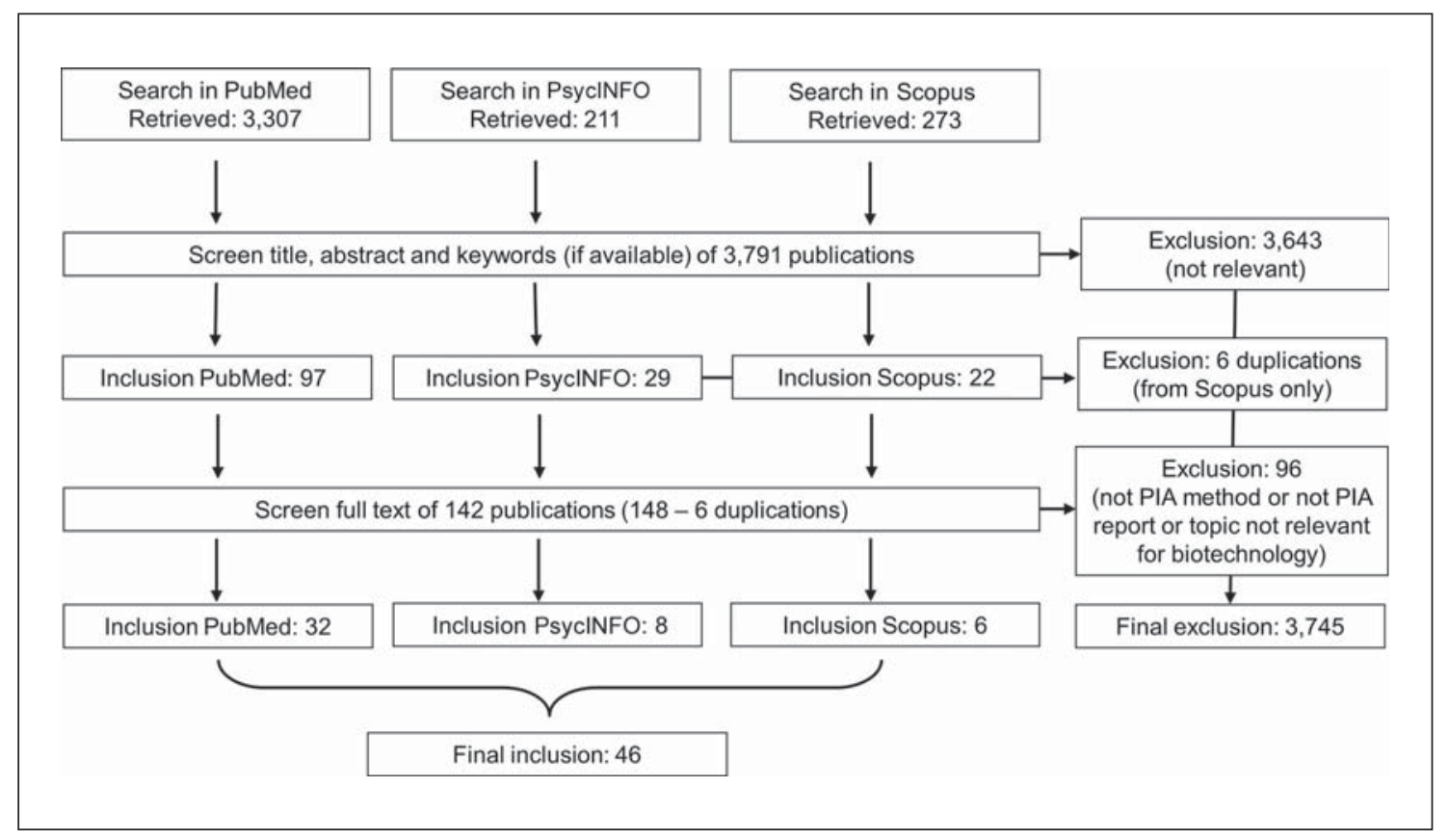

Fig. 1. Selection of publications.

Table 1. Full search terms for systematic search of PIA reports in the three electronic databases

\section{PubMed}

((('Biomedical Research’[Mesh]) OR (((('Nanomedicine’[Mesh]) OR 'Individualized Medicine'[Mesh]) OR ‘Genetic Therapy'[Mesh]) OR ((((('Biotechnology'[Mesh]) OR ‘Cell Engineering'[Mesh]) OR 'Tissue Banks'[Mesh]) OR 'Synthetic Biology’[Mesh]) OR ‘Regenerative Medicine’[Mesh])) )) AND (((('Consumer Participation’) OR (((((('Public Engagement’) OR 'Public Participation') OR 'Public Involvement’) OR ‘Public Deliberation’) OR (Public Consultation’) OR 'Consumer Participation'[Mesh]))))

\section{PsycINFO}

exp Involvement/ or exp Community Involvement/ or Public Involvement.mp. or exp Public Opinion/ or Public Consultation.mp. or Public Engagement.mp. and exp Genetics/ or exp Bioethics/ or exp Informed Consent/ or Biomedical Research.mp. or Biotechnology. mp. or exp Biotechnology/

\section{Scopus}

TITLE-ABS-KEY(Biotechnology) OR TITLE-ABS-KEY('Biomedical Research') AND TITLE-ABS-KEY('Public Involvement') OR TITLE-ABS-KEY('Public Engagement') OR TITLE-ABS-KEY('Public Participation') OR TITLE-ABS-KEY('Public Consultation')

For the analysis of representation concepts and corresponding recruitment criteria and methods, we extracted text passages on (a) sampling/representation objectives, (b) eligibility criteria and recruiting methods for selecting the sample and (c) the type of representation actually achieved by the recruited sample (online suppl. information 2). The last included discussions on potential sample/representation limitations and how such limitations were addressed.

The included reports were assessed by four researchers (J.L., I.H., T.H. and S.B.) by extracting relevant text passages. These were coded to allow for qualitative and quantitative synthesis of the re- sults. More details on the development of the analysis matrix and on data analysis have been published elsewhere [24].

\section{Analysis of Representation Concepts}

We applied four core concepts of representation for the thematic text analysis of representation aims and outcomes. The four concepts stem from internationally established theoretical frameworks for deliberative democracy, normative deliberative theory and the concept of representation as such (table 2). Based on the specific objective of a PIA study, the desired type of representation may vary. For instance, in one PIA on synthetic biology, partici- 
Table 2. Concepts of representation

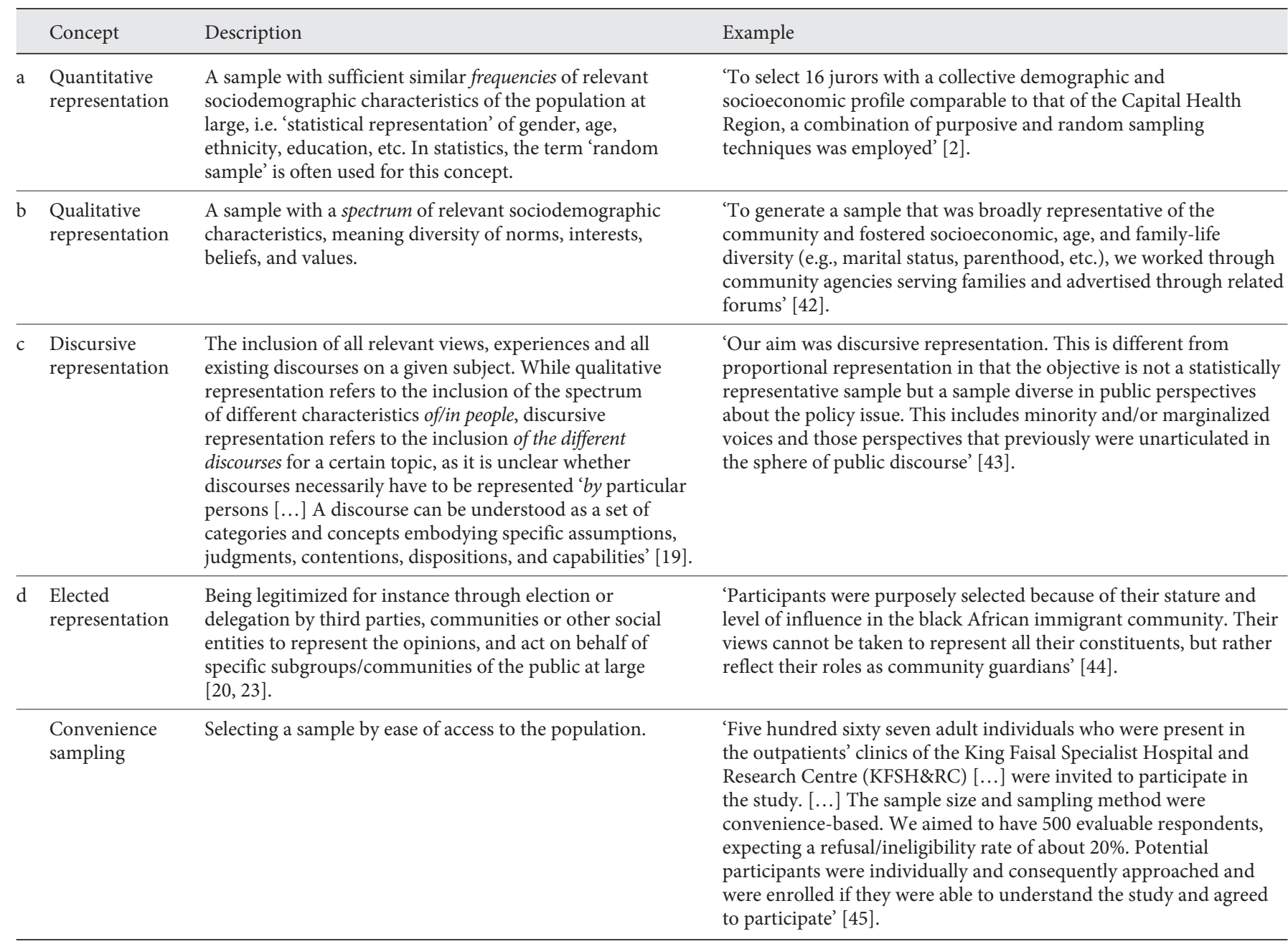

pants were selected according to 'different natural groups who meet on a regular basis, share a common identity (such as being members of an organisation or NGO), and hence are likely to represent relevant real-life conversation partners for each other when discussing new and unfamiliar issues' [29]. In another PIA that aimed to assess attitudes on human cloning, the sample was intended 'to reflect the demographic profile of the populations in the various group locations' [30].

In addition to the four types of representation, some PIAs may not have such specific concepts/representation aims, but rather recruit easily accessible participants. This approach to selecting study participants is commonly understood as convenience sampling. That is, study participants take part because of their easy availability, or because they independently decide to take part in the PIA, for example when spontaneously joining a survey conducted during a fair.

While 'random sampling' is often used as a synonym for 'quantitative representation', we did not combine those studies that aimed at a random sample with those that aimed at quantitative representation, in order to avoid making interpretative judgments. Instead, quantitative representation and random samples were assessed individually.

Studies that aimed either at qualitative or discursive representation were distinguished based on their respective criteria and definitions [31]. Qualitative as well as discursive representation both aim at a diverse composition of the study population instead of a proportionally correct reflection of the target population at large. Still, each concept relates to a distinct form of diversity: discursive representation requires the inclusion of all relevant perspectives and rationales regarding the study topic [19]. Qualitative representation requires diversity of study participants' sociodemographic characteristics. Often, qualitative representation is considered as a proxy for discursive representation, assuming that persons with different sociodemographic characteristics also entail different perspectives and rationales. Hence, it may be difficult to distinguish whether studies aim at qualitative or discursive representation. The authors (J.L. and S.B.) discussed studies that were difficult to classify separately and con- 
sented on the classification to further limit possible risks of misclassification.

To give an example for challenging classifications, a PIA study on biobank research aimed to 'reflect the range of diversity found in [British Columbia]' [3]. This apparently relates to qualitative diversity in terms of the samples' characteristics, rather than a diverse spectrum of views on a given subject. Another study mentions 'our aim was discursive representation' and 'a sample diverse in public perspectives'. Still, it also mentions '[... ] a lack of sociodemographic diversity which is problematic, because this indicator was adopted as a proxy measure of discursive representation' [32]. This example may relate to discursive representation, given that sociodemographic diversity was intended as proxy to achieve the (discursive) representation aim, and not vice versa.

\section{Results}

Of the 46 studies analyzed, 20 (43\%) focused on issues in genetics and genomics and another 18 (39\%) on biobank research that often includes genetics research. Further foci were on general biomedical research $(n=5)$ and bloodspot sample research $(\mathrm{n}=3)$. Synthetic biology, nanotechnology and human cloning research were mentioned once, respectively. 13 PIAs (28\%) referred to more than one subject.

\section{Representation Objectives}

Seven PIAs (15\%) aimed to achieve quantitative representation in their study samples, meaning sufficiently similar frequencies of relevant sociodemographic characteristics to those of the population at large. For example, one study reported that ' $[\mathrm{t}] \mathrm{h}$ e survey sample was designed according to Department of Statistics guidelines using the 2004 Population and Housing Census to ensure that the final sample reflected the socioeconomic and demographic distribution of Jordan' [33].

Further, 8 studies (17\%) aimed for a random sample. While random sampling is understood as a method to achieve quantitative representation, these studies did not directly mention quantitative representation, but referred to the random sampling methodology only.

15 studies (33\%) aimed for qualitative representation by reflecting the spectrum of views, norms and preferences towards biomedical research. (One study claimed to aim at both quantitative and qualitative representation, as the PIA included different phases with different objectives and methods.) This included for example '[...] the objective is not a statistically representative sample but a sample diverse in public perspectives' [32] and '[focus] group members were recruited to reflect a range of demographics, including age, education, race, ethnicity, gender, and socioeconomic status [...]' [34] (for text-based examples on representation objectives and outcomes extracted from the original PIA studies, see online suppl. information 3).

Five studies (11\%) reported a sample aim which would qualify either as elected representation $(n=1)$ or discursive representation $(n=4)$.

Eight studies (17\%) reported having recruited their samples by convenience. This was done for example by recruiting '[...] 45 African-American adults whose children received medical care at two healthcare facilities on the South Side of Chicago that serve different socioeconomic communities' [35] or '[t]he survey questionnaire was attached to the monthly magazine entitled, "Machiapo" (in Japanese) which is targeted for patients and distributed to pharmacies with a circulation of 150,000 throughout Japan' [36].

Four studies (9\%) reported neither representation objectives nor recruiting methods that would hint at a particular type of representation, or even aiming at some partial degree of diverse views and norms, or different sociodemographic characteristics (table 3 ).

\section{Recruitment Process}

40 studies (87\%) reported the use of eligibility criteria to achieve the intended concept of representation. Of these, 7 studies defined one criterion such as minimum age or language spoken, and the remaining 33 studies defined two or more criteria, such as 'adult Egyptian patients', excluding those 'who were critically ill or with diminished decisional capacity' [37].

In total, 31 broadly distinguishable criteria were mentioned among the 46 PIA studies, which can be differentiated as criteria related to (a) demography, e.g. age, ethnicity, religion $(\mathrm{n}=11)$, (b) status function/role, e.g. lay person, community leader $(\mathrm{n}=7)$, (c) relation to research, e.g. no previous participation, previously refused to participate in research $(n=6),(d)$ health, health status, risk behavior $(\mathrm{n}=5)$ or $(\mathrm{e})$ 'technical' availability, access to email and telephone $(\mathrm{n}=2)$.

21 PIA studies reported recruiting the study sample in deliberately chosen places such as hospitals or via personal contacts such as the board of a community organization. 17 studies instead described a random recruiting process, for example via residential telephone numbers, random invitation by letter or random selection from hospital registration files. Of these, 5 studies delegated the recruiting process to an external company, such as an 'external market research agency' [32] or a 'public opinion research firm' [4]. Eight PIA studies did not report their recruiting method. 
Table 3. Reporting of representation (repr.) aims and outcomes - quantitative findings

\begin{tabular}{|c|c|c|c|c|c|c|c|c|c|}
\hline \multirow[t]{2}{*}{$\begin{array}{l}\text { Representation aim or } \\
\text { sampling method }\end{array}$} & \multicolumn{4}{|c|}{$\begin{array}{l}\text { Reporting of representation aims and sampling } \\
\text { methods }^{1}\end{array}$} & \multicolumn{5}{|c|}{ Reporting of representation outcomes ${ }^{2}$} \\
\hline & aim & method & $\begin{array}{l}\text { quantitative } \\
\text { repr. } \\
\text { achieved }\end{array}$ & $\begin{array}{l}\text { qualitative } \\
\text { repr. } \\
\text { achieved }\end{array}$ & $\begin{array}{l}\text { discursive } \\
\text { repr. } \\
\text { achieved }\end{array}$ & $\begin{array}{l}\text { elected } \\
\text { repr. } \\
\text { achieved }\end{array}$ & $\begin{array}{l}\text { not } \\
\text { specified }\end{array}$ & $\begin{array}{l}\text { not } \\
\text { achieved }\end{array}$ & $\begin{array}{l}\text { discussion of } \\
\text { repr./sampling } \\
\text { limitations }\end{array}$ \\
\hline $\begin{array}{l}\text { Quantitative representation or } \\
\text { random sample }\end{array}$ & 7 & 8 & $7(5 / 2)$ & & & & $7(2 / 5)$ & $2(1 / 1)$ & 2 \\
\hline Discursive representation & 4 & & & & 0 & & 1 & 3 & 3 \\
\hline Elected representation & 1 & & & & & 1 & & & 1 \\
\hline $\begin{array}{l}\text { Convenience sampling without } \\
\text { specification of representation aim }\end{array}$ & & 8 & & & & & 1 & 7 & 2 \\
\hline $\begin{array}{l}\text { No specification of representation } \\
\text { aim or sampling method }\end{array}$ & 4 & & 1 & & & & 2 & 1 & \\
\hline
\end{tabular}

${ }^{1}$ Representation aims/methods include one study that mentions more than one aim, hence $\mathrm{n}=47$ instead of $\mathrm{n}=46 .{ }^{2}$ The total sum of 48 studies (representation outcomes) is due to two studies that mention more than one representation outcome, hence $\mathrm{n}=48$ instead of $\mathrm{n}=46$.

Of all studies that reported eligibility criteria or recruiting methods, 5 explicitly justified their criteria ( $\mathrm{n}=$ 3 ) or recruiting methods $(n=2)$ with respect to their representation objective, such as 'a random process for the selection of patients [...] to ensure age, gender and socioeconomic diversity' [38] or 'groups were purposively sampled and chosen to reflect a range of demographics [...] aiming for diversity rather than representation' [1].

\section{Sampling Properties and Representation Achieved}

Eight studies claimed to have achieved quantitative representation; for instance, '[i]n comparison to the Australian Bureau of Statistics (ABS) Census data for 2006, the sample was representative of the Australian population in terms of state, education and occupation, but was over-represented by older individuals [...] and females. The data were therefore weighted according to ABS (2006) proportions for gender and age groups' [38].

Qualitative representation was claimed in 3 PIA reports, such as ' $[t]$ he diversity of socioeconomic and occupational backgrounds of the participants is shown in table 1. Our sample consisted of almost equal proportions of MalayMuslims, Chinese, and Indians with a wide range in age (18-62 years), educational level and occupation' [39] - one of these studies claimed both qualitative and quantitative representation. Lastly, success in discursive representation was not claimed in any of the 4 PIA reports that aimed for it. Success in elected representation was reported once.
General (quantitative) participant characteristics were provided in 37 studies by reporting statistical information such as age, gender and ethnicity. However, from these data alone it could not be indicated if they were meant to state whether representation was achieved or not.

17 studies reported to not have achieved representation, although all of these mentioned a specific sampling aim, or at least a sampling method indicating an aim. The representation aims or methods of these 17 studies were as follows: qualitative representation $(\mathrm{n}=4)$, discursive representation $(\mathrm{n}=3)$, quantitative representation $(\mathrm{n}=$ 2), random sampling $(\mathrm{n}=1)$ and convenience sampling/ self-selection $(\mathrm{n}=7)$.

While all these 17 studies did mention that representation was not achieved, 9 reported only that representation was not achieved, but did not provide any further information as to the actual type of representation that was not achieved. For instance, one study mentioned that ' [...] the focus groups cannot be said to be truly representative [...]' [30] without indicating whether this related for instance to quantitative or qualitative representation.

Ten of these 17 studies addressed potential consequences of this limitation in their 'study limitations' section. These limitations either referred to difficulties in generalizing and extrapolating the results to other contexts $(n=5)$, changing demographic characteristics and diversity of the population not reflected in the sample $(n=3)$, concerns that other individuals outside the study 
population would have different views on the subject of discussion/consultation $(n=1)$ and the necessity of validation of the results in larger samples $(n=1)$. Such limitations were expressed for example by ' $[w]$ hile the study sample demographics may reflect those who are currently interested in personal genomics [...], these findings cannot be extended to the general population that may encounter personal genomics either in retail stores or in a physician's office in years to come' [40] and '[the results] should not be taken as representing the perspectives of African Americans or Latinos/Latinas nationally' [41].

19 studies did not specify whether representation of the study sample vis-à-vis the population at large was achieved (table 3 ).

\section{Discussion}

Public involvement as a tool for the governance of ethically sensitive biomedical research and innovation has received increasing attention in the last decade. A core methodological question is whom exactly to involve in a PIA. The validity and value of any PIA depends on whether the sample of the involved subgroup of the 'public' is sufficiently representative. To demonstrate 'sufficient representation', it is of the utmost importance for PIA reports to describe (a) the intended representation objectives together with the eligibility criteria and recruiting methods used, (b) whether the intended representation objective is achieved and (c) potential limitations of the actual study sample. This is the first study to assess the reporting of different concepts of representation in a systematically derived sample of PIAs in biomedical research and innovation.

Of the 46 studies analyzed, 27 reported a specific representation objective and 8 at least a sampling method. This suggests that a majority of PIA authors are aware of the need to specify representation aims. Still, reporting a specific aim instead of just a sampling method may give a better account of representation. This makes it easier for instance to evaluate whether a sampling objective has actually been achieved, or to draw conclusions about a study's representativeness vis-à-vis the general population.

Further, the explicit reporting of eligibility criteria (in 40 studies, 87\%) and the specification of recruiting methods (in 38 studies, 83\%) appear to be well established for PIAs in biomedical research and innovation. However, only 5 studies (11\%) related recruiting criteria and meth-

Public Involvement Activities in

Biomedical Research and Innovation ods to representation objectives, despite their normative significance in PIAs. When planning a PIA, recruiting criteria and methods should be explicitly adjusted to the representation objective.

Lastly, of those 35 PIA reports that explicitly or implicitly described a representation objective, only $12(26 \%)$ specified that representation was achieved; 10 (22\%) discussed study limitations arising from representation issues regarding the sample, and their consequences for interpreting the results. The number of studies reporting to have achieved their representation objective varies between the different forms of representation. Of the 15 studies aiming at quantitative representation or random sampling, 8 report to have achieved their goal (53\%), of the 15 studies aiming at qualitative representation only 3 (20\%) claim successful representation, and none of the 4 studies aiming at discursive representation do so. Hence, qualitative and discursive representation may either be more challenging to accomplish, more difficult to prove, or authors of respective PIA reports often do not see the importance to critically discuss the success of their representation objectives. Especially for studies aiming at discursive representation, providing sound evidence for successful representation is challenging, as the presence of all relevant views and experiences is difficult to verify.

The consequences of limited representation as discussed in many of the analyzed PIA reports point at the challenging implementation of representation. Concerns were addressed regarding application and replication of results in other contexts or with other individuals due to the study samples' incomplete or incorrect portrayal of the population at large. To improve the representativeness of future PIA samples - irrespective of the intended form of representation - first, reasons for not accomplishing representation need to be identified and analyzed for different PIA methods. Second, recruitment procedures can be further developed and adapted to reduce biases in study populations.

A previously published analysis on the same sample of PIA reports revealed that translation of PIA results into policy and practice is currently little documented [24]. A more precise reporting of representation objectives, achieved levels of representation and its limitations could contribute to more successful translation of PIA results, since representation ensures that the views, interests and preferences of the population at large are reflected [15]. A systematic account of representation in PIA reports could also be facilitated by clearly addressing the theo$\mathrm{retical} /$ normative relevance of this concept, that is clarifying whether, why and what type of representation is rel- 
evant to the particular PIA. This could then help to highlight the impact of PIAs on decision-making processes in science and politics. Especially for discursive and qualitative representation this requires further clarification of their concepts as well as identification of unambiguous criteria for successful implementation.

\section{Conclusion}

The results of the current study provide a good argument for the development of reporting guidelines for PIAs on biomedical research and innovation. Former analyses on current reporting of PIAs' objectives, methods, translation of results and self-evaluation also revealed a respective need [7]. Besides improving reporting as such, the guidelines could also help PIA organizers to consider all relevant steps in the design, conduct and follow-up of a PIA.

To find out whether inconsistent and incomplete reporting of representation is due to PIA organizers' not prioritizing its reporting or not considering representation, future research could focus on consulting PIA organizers on this matter. In so doing, it may also be valuable to assess the importance that PIA practitioners actually place on defining, selecting and working with a specific concept of 'representation' and 'public' and to find out why these concepts are often defined and applied inconsistently.

To be considered a legitimate tool for providing input into research governance and policy-making, PIAs need improvement with regard to the reporting of representation aims and whether they were eventually achieved. Furthermore, the adequacy of the chosen eligibility criteria and recruitment methods should be justified with regard to the aims of the particular PIA.

\section{Acknowledgments}

This project was funded by intramural funds of Hannover Medical School and by the German Research Foundation (DFG) via the grant 'Cluster of Excellence 62, REBIRTH - From Regenerative Biology to Reconstructive Therapy' (http://www.dfg.de/ foerderung/programme/listen/projektdetails/index.jsp? $\mathrm{id}=24102914)$. The funders had no role in study design, data collection and analysis, decision to publish or preparation of the manuscript.

\section{Disclosure Statement}

The authors have no conflicts of interest to disclose.

\section{References}

1 Haddow G, Cunningham-Burley S, Bruce A, Parry S: Generation Scotland: consulting publics and specialists at an early stage in a genetic database's development. Crit Public Health 2008;18:139-149.

2 Menon D, Stafinski T: Engaging the public in priority-setting for health technology assessment: findings from a citizens' jury. Health Expect 2008;11:282-293.

-3 O’Doherty KC, Hawkins AK, Burgess MM: Involving citizens in the ethics of biobank research: informing institutional policy through structured public deliberation. Soc Sci Med 2012;75:1604-1611.

44 Godard B, Marshall J, Laberge C: Community engagement in genetic research: results of the first public consultation for the Quebec CARTaGENE project. Community Genet 2007;10:147-158.

5 Conklin A, Morris Z, Nolte E: What is the evidence base for public involvement in healthcare policy?: results of a systematic scoping review. Health Expect 2015;18:153-165.
6 Abelson J, Blacksher EA, Li KK, Boesveld SE, Goold SD: Public deliberation in health policy and bioethics: mapping an emerging, interdisciplinary field. J Public Delib 2013;9:article 5.

7 Avard D, Bucci L, Burgess M, Kaye J, Heeney C: Public health genomics (PHG) and public participation: points to consider. J Public Delib 2009;5:article 7.

8 Kampourakis K, Vayena E, Mitropoulou C, van Schaik RH, Cooper DN, Borg J, Patrinos GP: Key challenges for next-generation pharmacogenomics: Science \& Society series on Science and Drugs. EMBO Rep 2014;15:472-476.

-9 Reydon TA, Kampourakis K, Patrinos GP: Genetics, genomics and society: the responsibilities of scientists for science communication and education. Pers Med 2012;9:633643.

10 Mai Y, Koromila T, Sagia A, Cooper DN, Vlachopoulos G, Lagoumintzis G, Kollia P, Poulas K, Stathakopoulos V, Patrinos GP: A critical view of the general public's awareness and physicians' opinion of the trends and potential pitfalls of genetic testing in Greece. Pers Med 2011;8:551-561.
11 Rowe G, Frewer LJ: A typology of public engagement mechanisms. Sci Technol Human Values 2005;30:251-290.

12 Nuffield Council on Bioethics: Emerging biotechnologies: Technology, Choice and the Public Good. 2012. http://nuffieldbioethics. org/project/emerging-biotechnologies/.

13 Mohr A, Raman S: Representing the public in public engagement: the case of the 2008 UK Stem Cell Dialogue. PLoS Biol 2012;10: e1001418.

14 Barnett C, Mahony N: Segmenting publics Executive Summary. 2011. http://www.esrc. ac.uk/files/public-engagement/public-dialogues/full-report-segmenting-publics.

15 Patient-Centered Outcomes Research Institute: The PCORI methodology report. 2013. http://www.pcori.org/assets/2013/11/PCORI-Methodology-Report.pdf.

16 Abelson J, Forest PG, Eyles J, Smith P, Martin E, Gauvin FP: Deliberations about deliberative methods: issues in the design and evaluation of public participation processes. Soc Sci Med 2003;57:239-251. 
17 Longstaff H, Burgess MM: Recruiting for representation in public deliberation on the ethics of biobanks. Public Underst Sci 2010;19: 212-224.

18 Martin GP: 'Ordinary people only': knowledge, representativeness, and the publics of public participation in healthcare. Sociol Health Illn 2008;30:35-54.

19 Dryzek JS, Niemeyer S: Discursive representation. Am Polit Sci Rev 2008;102:481-493.

20 Parkinson J: Deliberating in the Real World: Problems of Legitimacy in Deliberative Democracy. Oxford, Oxford University Press, 2006, 221 pp.

$>21$ Brown MB: Survey article: Citizen panels and the concept of representation. J Polit Philos 2006; 14:203-225.

-22 Litva A, Coast J, Donovan J, Eyles J, Shepherd M, Tacchi J, Abelson J, Morgan K: 'The public is too subjective': Public involvement at different levels of health-care decision making. Soc Sci Med 2002;54:1825-1837.

$>23$ Parkinson J: Legitimacy problems in deliberative democracy. Polit Stud 2003;51:180-196.

-24 Lander J, Hainz T, Hirschberg I, Strech D: Current practice of public involvement activities in biomedical research and innovation: a systematic qualitative review. PLoS One 2014; 9:e113274.

-25 Rowe G, Frewer LJ: Public participation methods: a framework for evaluation. Sci Technol Human Values 2000;25:3-29.

26 Nanz P, Fritsche M: Handbuch Bürgerbeteiligung: Verfahren und Akteure, Chancen und Grenzen. Bonn, Bundeszentrale für Politische Bildung, 2012 [Schriftenreihe/Bundeszentrale für Politische Bildung, vol. 1200].

27 Organization for Economic Cooperation and Development: Evaluating Public Participation in Policy Making. 2005. http://www. oecd.org/gov/evaluatingpublicparticipationinpolicymaking.htm.

28 Warburton D, Wilson R, Rainbow E: Making a Difference: A guide to evaluating public participation in central government. 2011. http:// www.involve.org.uk/evaluation-guide/.

$>29$ Kronberger N, Holtz P, Wagner W: Consequences of media information uptake and deliberation: focus groups' symbolic coping with synthetic biology. Public Underst Sci 2012;21:174-187.

>30 Shepherd R, Barnett J, Cooper H, Coyle A, Moran-Ellis J, Senior V, Walton C: Towards an understanding of British public attitudes concerning human cloning. Soc Sci Med 2007;65:377-392.

-31 Hainz T, Bossert S, Strech D: Collective agency and the concept of 'public' in public involvement: a practice-oriented analysis. BMC Med Ethics 2016;17:48.

-32 Molster C, Maxwell S, Youngs L, Potts A, Kyne G, Hope F, Dawkins H, O’Leary P: An Australian approach to the policy translation of deliberated citizen perspectives on biobanking. Public Health Genomics 2012;15: 82-91.
33 Ahram M, Othman A, Shahrouri M: Public support and consent preference for biomedical research and biobanking in Jordan. Eur J Hum Genet 2013;21:567-570.

34 Murphy J, Scott J, Kaufman D, Geller G, LeRoy L, Hudson K: Public perspectives on informed consent for biobanking. Am J Public Health 2009;99:2128-2134.

35 Halverson CM, Ross LF: Attitudes of AfricanAmerican parents about biobank participation and return of results for themselves and their children. J Med Ethics 2012;38:561-566.

36 Kobayashi E, Sakurada T, Ueda S, Satoh N: Public involvement in pharmacogenomics research: a national survey on patients' attitudes towards pharmacogenomics research and the willingness to donate DNA samples to a DNA bank in Japan. Cell Tissue Bank 2011;12:7180.

37 Abou-Zeid A, Silverman H, Shehata M, Shams M, Elshabrawy M, Hifnawy T, Rahman SA, Galal B, Sleem H, Mikhail N, Moharram $\mathrm{N}$ : Collection, storage and use of blood samples for future research: views of Egyptian patients expressed in a cross-sectional survey. J Med Ethics 2010;36:539-547.

38 Nicol D, Critchley C: Benefit sharing and biobanking in Australia. Public Underst Sci 2012; 21:534-555.

39 Wong ML, Chia KS, Wee S, Chia SE, Lee J, Koh WP, Shen HM, Thumboo J, Sofjan D: Concerns over participation in genetic research among Malay-Muslims, Chinese and Indians in Singapore: a focus group study. Community Genet 2003;7:44-54.

40 Gollust SE, Gordon ES, Zayac C, Griffin G, Christman MF, Pyeritz RE, Wawak L, Bernhardt BA: Motivations and perceptions of early adopters of personalized genomics: perspectives from research participants. Public Health Genomics 2011;15:22-30.

-41 Schulz A, Caldwell C, Foster S: 'What are they going to do with the information?' Latino/Latina and African American perspectives on the Human Genome Project. Health Educ Behav 2003;30:151-169.

42 Bombard Y, Miller FA, Hayeems RZ, Carroll JC, Avard D, Wilson BJ, Little J, Bytautas JP Allanson J, Axler R, Giguere Y, Chakraborty $\mathrm{P}$ : Citizens' values regarding research with stored samples from newborn screening in Canada. Pediatrics 2012;129:239-247.

43 Molster C, Maxwell S, Youngs L, Kyne G, Hope F, Dawkins H, O'Leary P: Blueprint for a deliberative public forum on biobanking policy: were theoretical principles achievable in practice? Health Expect 2013;16:211-224.

44 Buseh AG, Underwood SM, Stevens PE, Townsend L, Kelber ST: Black African immigrant community leaders' views on participation in genomics research and DNA biobanking. Nurs Outlook 2013;61:196-204.

45 Al-Qadire MM, Hammami MM, Abdulhameed HM, Al Gaai EA: Saudi views on consenting for research on medical records and leftover tissue samples. BMC Med Ethics 2010;11:18.
46 Botkin JR, Rothwell E, Anderson R, Stark L, Goldenberg A, Lewis M, Burbank M, Wong B: Public attitudes regarding the use of residual newborn screening specimens for research. Pediatrics 2012;129:231-238.

47 Ulrich A, Thompson B, Livaudais JC, Espinoza N, Cordova A, Coronado GD: Issues in biomedical research: what do Hispanics think? Am J Health Behav 2013;37:80-85

48 Berth H, Balck F, Dinkel A: Attitudes toward genetic testing in patients at risk for HNPCC/ FAP and the German population. Genet Test 2002;6:273-280.

49 Miller FA, Mentzakis E, Axler R, Lehoux P, French M, Tarride J, Wodchis WP, Wilson BJ, Longo C, Bytautas JP, Slater B: Do Canadian researchers and the lay public prioritize biomedical research outcomes equally? A choice experiment. Acad Med 2013;88:519-526.

50 Rothwell E, Anderson R, Goldenberg A, Lewis $\mathrm{MH}$, Stark L, Burbank M, Wong B, Botkin JR: Assessing public attitudes on the retention and use of residual newborn screening blood samples: a focus group study. Soc Sci Med 2012;74:1305-1309.

51 Marsh V, Kombe F, Fitzpatrick R, Molyneux S, Parker M: Managing misaligned paternity findings in research including sickle cell disease screening in Kenya: 'consulting communities' to inform policy. Soc Sci Med 2013;96: 192-199.

-52 Terry SF, Christensen KD, Metosky S, Rudofsky G, Deignan KP, Martinez H, JohnsonMoore P, Citrin T: Community engagement about genetic variation research. Popul Health Manag 2012;15:78-89.

53 Godard B, Ozdemir V, Fortin M, Egalité N: Ethnocultural community leaders' views and perceptions on biobanks and population specific genomic research: a qualitative research study. Public Underst Sci 2010;19:469-485.

54 Bernhardt BA, Tambor ES, Fraser G, Wissow LS, Geller G: Parents' and children's attitudes toward the enrollment of minors in genetic susceptibility research: implications for informed consent. Am J Med Genet A 2003; 116A:315-323.

55 Kerath SM, Klein G, Kern M, Shapira I, Witthuhn J, Norohna N, Kline M, Baksh F, Gregersen P, Taioli E: Beliefs and attitudes towards participating in genetic research - a population based cross-sectional study. BMC Public Health 2013;13:114.

56 McCarty CA, Chapman-Stone D, Derfus T, Giampietro PF, Fost N: Community consultation and communication for a populationbased DNA biobank: the Marshfield clinic personalized medicine research project. Am J Med Genet A 2008;146A:3026-3033.

57 Murphy J, Scott J, Kaufman D, Geller G, LeRoy L, Hudson K: Public expectations for return of results from large-cohort genetic research. Am J Bioeth 2008;8:36-43.

58 Bates BR, Harris TM: The Tuskegee Study of Untreated Syphilis and public perceptions of biomedical research: a focus group study. J Natl Med Assoc 2004;96:1051-1064.
Public Involvement Activities in

Biomedical Research and Innovation
Public Health Genomics 2016;19:193-202 
59 Mfutso-Bengo J, Ndebele P, Jumbe V, Mkunthi M, Masiye F, Molyneux S, Molyneux M: Why do individuals agree to enrol in clinical trials? A qualitative study of health research participation in Blantyre, Malawi. Malawi Med J 2008;20:37-41.

-60 Goldenberg AJ, Hull SC, Botkin JR, Wilfond BS: Pediatric biobanks: approaching informed consent for continuing research after children grow up. J Pediatr 2009;155:578583 .
61 Nisselle A, Forbes R, Bankier A, Hughes E, Aitken M: Consumer contribution to the delivery of genetic health services. Am J Med Genet A 2008;146A:2266-2274.

62 O’Daniel JM, Rosanbalm KD, Boles L, Tindall GM, Livingston TM, Haga SB: Enhancing geneticists' perspectives of the public through community engagement. Genet Med 2012;14: 243-249.

63 Roberts LW, Warner TD, Geppert CM, Rogers M, Green Hammond KA: Employees' perspectives on ethically important aspects of genetic research participation: a pilot study. Compr Psychiatry 2005;46:27-33.
64 Isler MR, Sutton K, Cadigan RJ, Corbie-Smith G: Community perceptions of genomic research: implications for addressing health disparities. N C Med J 2013;74:470-476.

65 Molyneux CS, Wassenaar DR, Peshu N, Marsh K: 'Even if they ask you to stand by a tree all day, you will have to do it (laughter)...!': community voices on the notion and practice of informed consent for biomedical research in developing countries. Soc Sci Med 2005;61:443-454. 